\title{
RocFall Analysis: The Distance and Size of Rock Fall from Brighton to Eastbourne
}

\author{
Reem Saghir \\ School of Earth and Environment, The University of Leeds, Leeds, UK \\ Email: reemsag@hotmail.com \\ Received 3 April 2014; revised 13 May 2014; accepted 23 June 2014 \\ Copyright (C) 2014 by author and OALib. \\ This work is licensed under the Creative Commons Attribution International License (CC BY). \\ http://creativecommons.org/licenses/by/4.0/ \\ (c) (i) Open Access
}

\begin{abstract}
A study was performed along $30 \mathrm{~km}$ distance of the coast of South England to estimate the size of falling blocks and their extent using RocFall and other computer programmes. In addition to computer analysis, observational analysis was used to identify many factors affecting the size and the end point of falling rocks. The analysis was based along the coastal Chalk cliffs from Brighton to Eastbourne. It involved measurements of dip and dip direction, classification and characteristics of rocks as well as noting the history of previous rock fall in relation to the extent and size. Nine areas were examined and reported according to their location except for Brighton which was divided according to the cliff protection methods used. For each area a cliff profile was drawn and information about its height, cliff sloping angle, geological formations, and type of cliff protection used, if any, were listed. Types of common failures were also identified from observation during site reconnaissance and from performed failure analysis using Dips programme. As a result, falling block size and rocks end point, to the worst case, could be estimated and judgment about the efficiency of protection methods used in protected areas has been made.
\end{abstract}

\section{Keywords}

RocFall, Coastal Cliffs, Chalk, Protection Methods, Rock Failure

Subject Areas: Environmental Sciences, Geology

\section{Introduction}

Many factors influence cliff stability and result, with time, in cliff retreat. Chalk is formed from millions of submicroscopic marine algae which makes it weaker than other carbonate rocks (Mortimore et al., 2001) [1]. It is also composed of clay-silt sized particles and of minor amount of clay content which enables it to retain high amount of moisture and causes it to expand and swell (Bell, 2007) [2]. Chalk has both low density and strength that are highly affected by weathering and erosion. Freeze, thaw, thermal, and salt weathering seasonally affect 
the chalky cliffs and result in widening fractures and joints along different lithological formations. In addition, other weather conditions such as rain and snow affect cliffs stability in either adding weight to the slope and thus increase the stresses acting on it, or by weakening the internal properties of chalk causing a reduction in its shear strength (Cheng, 2008) [3].

The study area covers the coastal cliffs of Brighton, Saltdean, Peacehaven, Newhaven, Seaford, Cuckmere Haven, Birling Gap, Beachy Head, and Eastbourne from West to East respectively. The only protected sections in the examined areas were from Brighton to Peacehaven. Parts of Telescombe Cliffs in Saltdean were unprotected and the rest of the coastal sections from Newhaven to Eastbourne were unprotected as well. Figure 1 shows a location map and a satellite image of the nine areas. The study involved an analysis of the size and extent of rock fall for coastal cliffs in each area using RocFall program. The block size was obtained by converting the energy of falling rocks into an equivalent size in $\mathrm{kg}$ and the end points were calculated by the program. The data collected during site reconnaissance aided another type of analysis; observational analysis. Out of observing the results of throwing couple of rock masses on different ground materials, it was noted that there are many factors affecting the size and extent of rock fall.

\section{Factors Affecting Size and Extent of Rock Fall}

\subsection{Mass of Falling Rocks}

The mass of falling rocks affects the distance of end point by affecting the bouncing behaviour of rocks. A rock with a great mass tends to bounce less than a lighter rock because larger rocks have greater forces. A small rock will impose a force less than that of the ground surface which will result in its rebound while a larger rock tends to impose a force close to that of the ground surface and as a result it will settle.

\subsection{Height from Where Rocks Are Falling}

The falling height also affects the bouncing behaviour of rocks, thus affects the end point. Rocks falling from a higher cliff for example, Beachy Head Cliffs will have greater bounce and thus reach longer distances than rocks falling from Newhaven cliffs that are 1/3 the height of Beachy Head Cliffs.

\subsection{Shape of Falling Rocks}

Irregular shapes of rocks tend to bounce randomly and have higher angular velocities which result in reaching longer distance when falling. Rocks falling on their flat surface on the other hand, tend to bounce less when landing on the ground surface. This can be explained by energy transfer. A rock with a flat surface will have more contact with the ground surface and more energy consumption will be involved while a rock landing on its edge will have less contact area with the ground surface and therefore very little energy will be consumed. As a result the remaining energy causes bouncing.

\subsection{Nature of Ground Surface}

Different surfaces have different values of coefficient of restitution (COR) which is a fractional value representing the ratio of speeds before and after an impact. COR represents the elasticity of the surface. For example, the same rock would bounce more if it landed on concrete rather than landing on sand because sand tends to have less value of COR (Särkkä and Eloranta, 2001) [4].
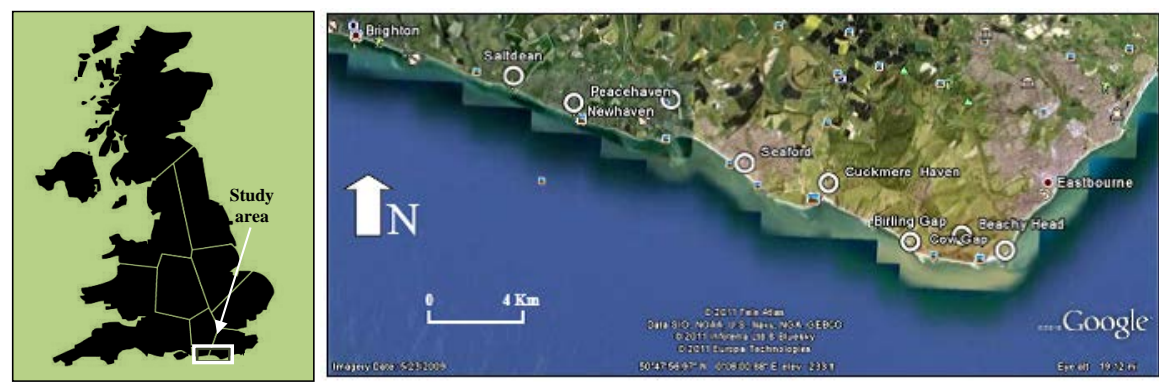

Figure 1. Location map and satellite image of the study area. 


\subsection{Cliff Roughness}

Cliff roughness affects the distance of dispatching rocks end point. The rougher the slope, the more bouncing rocks will encounter on the asperities of slope face during rolling down the cliff. A rock bouncing on a rough surface when falling will gain energy and this energy will then be transferred into bouncing after hitting the ground surface. This will cause rocks to travel longer distances.

\subsection{Fracturing}

Fracturing highly affects the end points of rocks. A fractured rock tends to break when falling from a cliff while a non fractured rock rests as a block over the ground surface. When failure occur in one of the fractured rock blocks, the block will break apart from the impact of collision with ground surface and might bounce reaching a longer distance than a non-fractured block would.

\subsection{Weather Conditions}

Weather conditions like heavy rain and wind affect the falling rocks end point in different ways. Rain for example will make the chalk lumpier and the falling block of chalk will not bounce as a dry chalk block would. Wind on the other hand, might result in a minor change in the direction and distance of failure.

\subsection{Type of Failure}

Toppling, planar, and wedge failures behave in different manners. Toppling failure takes place vertically and transfers to a horizontal position when landing (Figure 2(a)). Toppling thus results in the longest reaching distance of rocks end point. Planar and wedge failures (Figure 2(b) and Figure 2(c)) take place in a horizontal plane and are then falling vertically by the force of gravity. The longest distance rocks falling in planar and wedge failure might have is approximately equal to the depth of the falling block. If debris was involved in the failure, a longer distance is expected (a distance which is approximately equal to the height of the block).

\section{Analysis}

\subsection{Brighton (Shingle Beds)}

The most common failure in Brighton is small size rock fall resulting from rocks dispatching from the cliff face. According to RocFall analysis, about 35\% of falling rocks will land on the walk. Most falling rocks will land on the edge of the protective wall (Figure 3) and will then bounce either to the shingle bank or beyond it. The equivalent falling block size on the shingle bank is mostly less than $1 \mathrm{~kg}$. The maximum size of falling rocks might reach about $10 \mathrm{~kg}$ (Figure 4).

\subsection{Brighton (Catch-Nets)}

Catch-nets are really effective if they were $100 \%$ inelastic. With increasing elasticity bouncing increases and thus further landing should be expected.

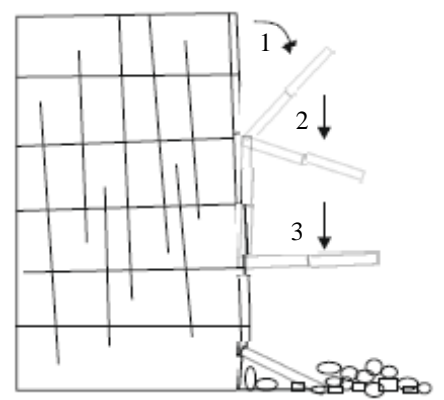

(a)

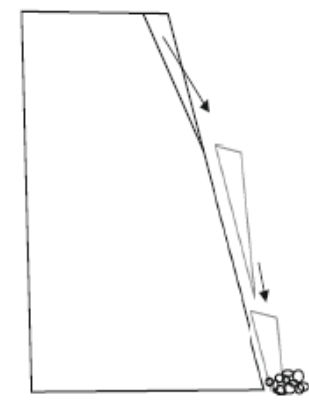

(b)

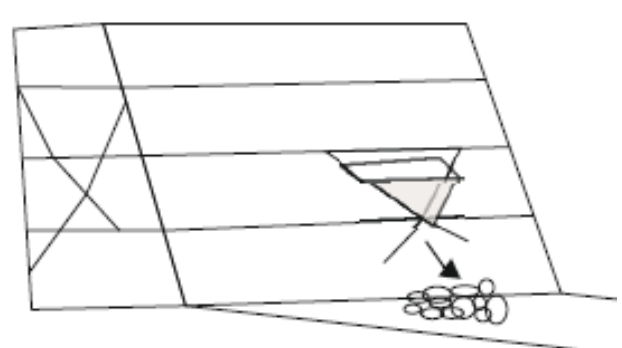

(c)

Figure 2. Rough drawing of rock end point for different failures (a) Toppling failure (b) Planar failure (c) Wedge failure. 


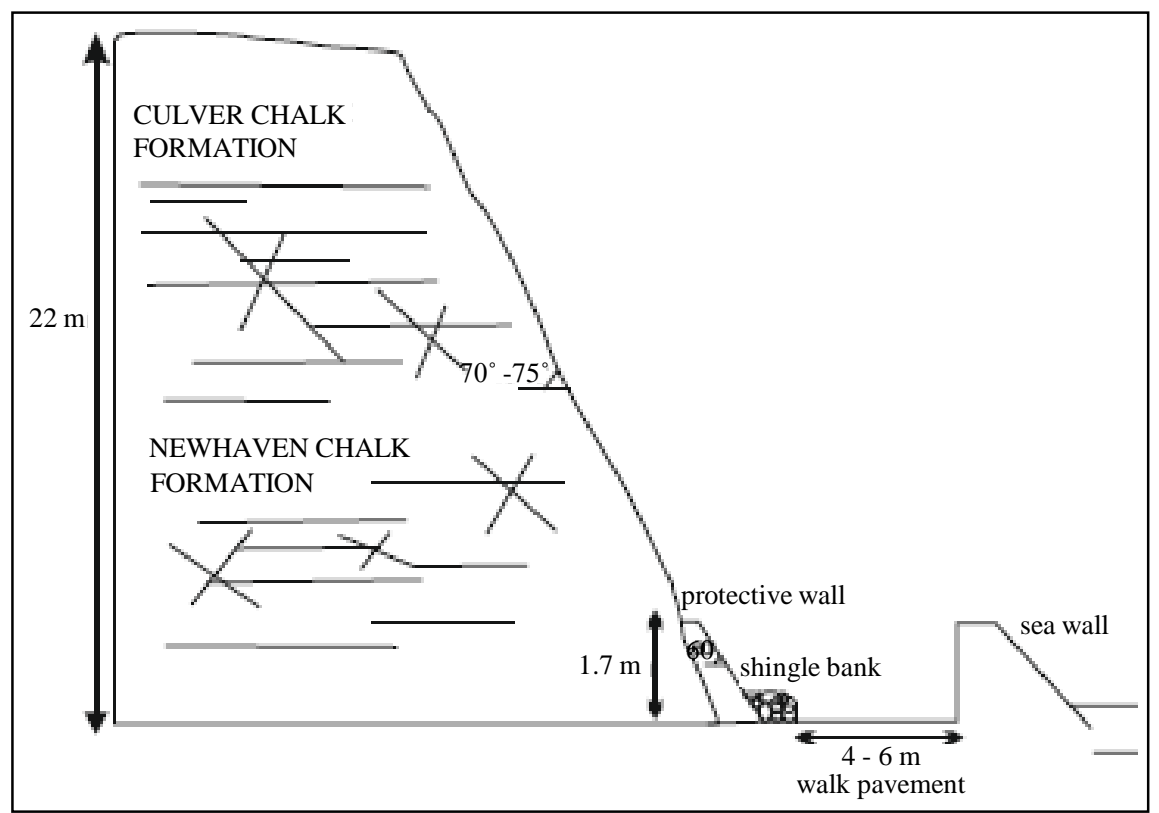

Figure 3. Drawing of cliff profile of Brighton under-cliff walk.

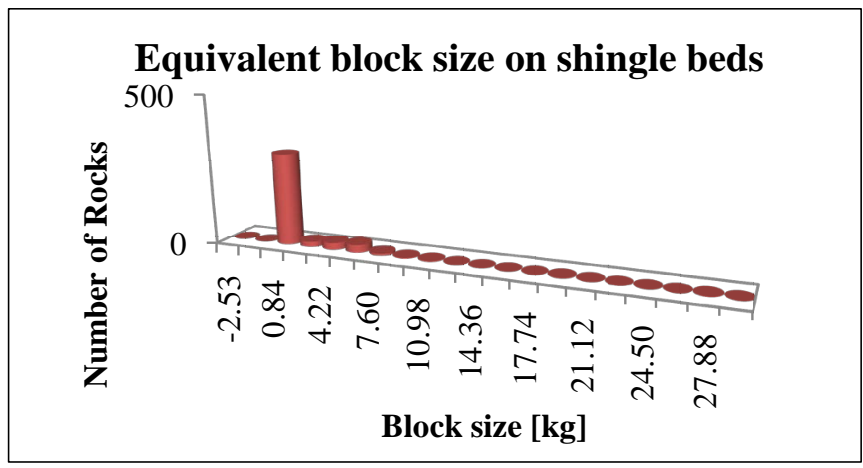

Figure 4. Equivalent block size for Brighton shingle beds.

The end point of rocks according to RocFall, with using a perfectly inelastic barrier (catch-net), is very close to the cliff face with a maximum distance of $1.5 \mathrm{~m}$ away from the cliff face (Figure 5). About 30\% of falling rocks are about $1 \mathrm{~kg}$ in size and the rest are between 5 and $20 \mathrm{~kg}$ (Figure 6). This means only 30\% of falling rocks will escape from the net down to the walk or protective wall and the rest of the $70 \%$ of rock falls will be repelled by the catch-net.

\subsection{Brighton (Fences)}

According to RocFall analysis, fences are effective for most of falling rocks. But about $10 \%$ of rocks might bounce and reach a distance further than the boundaries of fences (Figure 7). Almost $80 \%$ of the rocks will have an end point location at the fence boundary and $10 \%$ between the cliff and the fence. $50 \%$ of the falling rocks are about $0.5 \mathrm{~kg}$ in size but the block size might reach about $18 \mathrm{~kg}$ (Figure 8).

\subsection{Saltdean}

Rocks composing Saltdean Cliffs might fall in toppling, wedge, and/or planar manner. According to RocFall analysis most rocks fall to a distance between $2 \mathrm{~m}$ and $10 \mathrm{~m}$ away from the cliff face (Figure 9). The maximum distance rocks might reach is $34 \mathrm{~m}$ away but the chance is only $2 \%$. The rock mass equivalent range between debris size and $100 \mathrm{~kg}$. Only a very small percentage of blocks have a mass of almost a $1000 \mathrm{~kg}$ (Figure 10). 


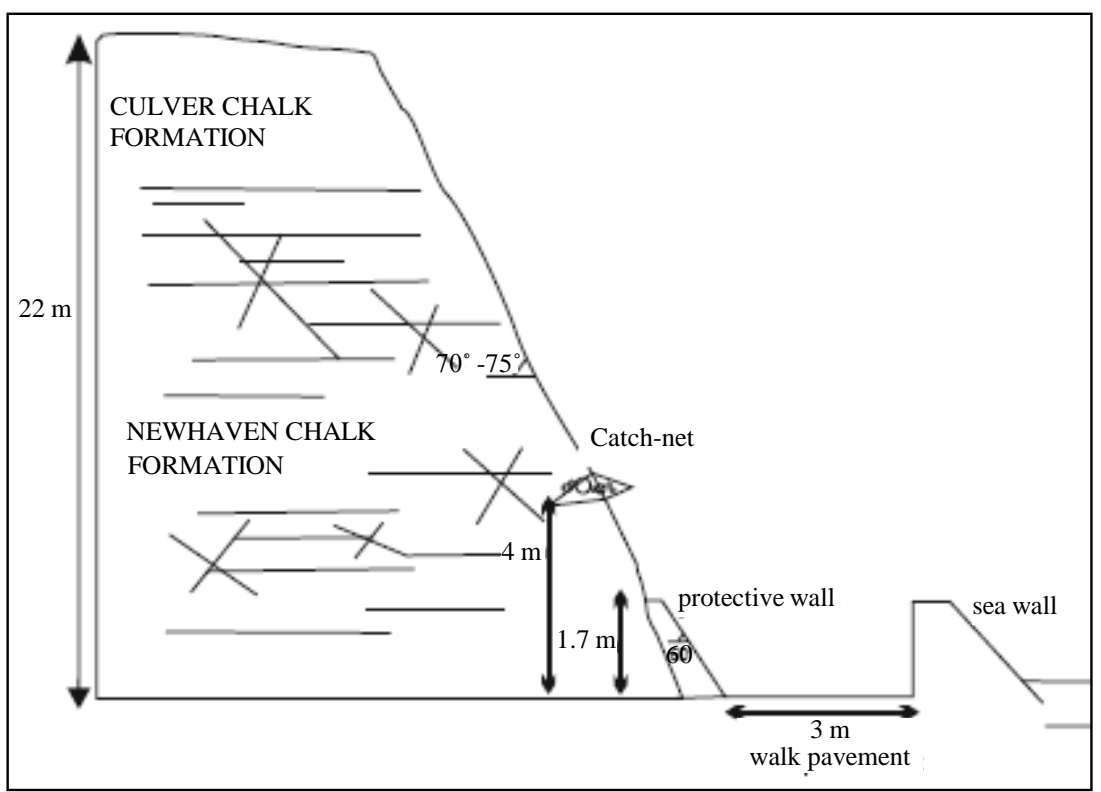

Figure 5. Drawing of cliff profile of Brighton under-cliff walk.

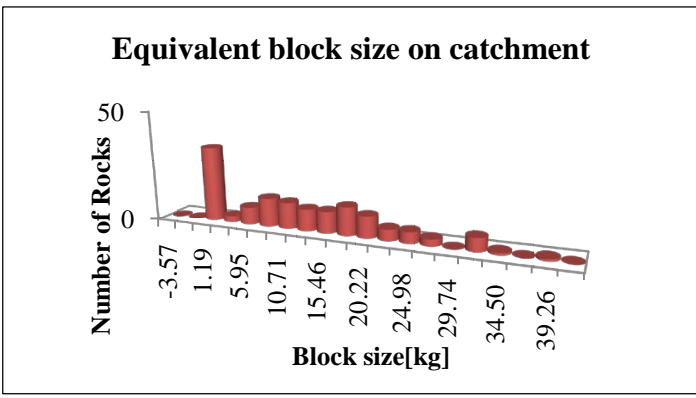

Figure 6. Equivalent block size for Brighton catch-nets.

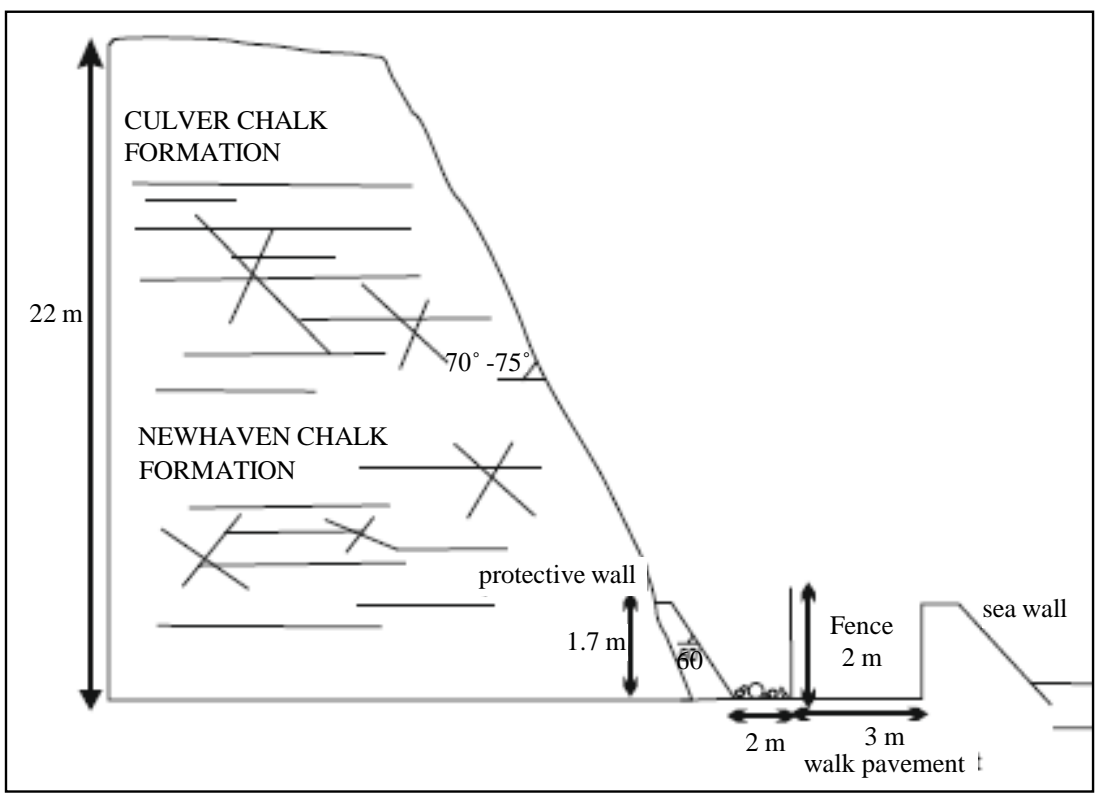

Figure 7. Drawing of cliff profile of Brighton under-cliff walk. 


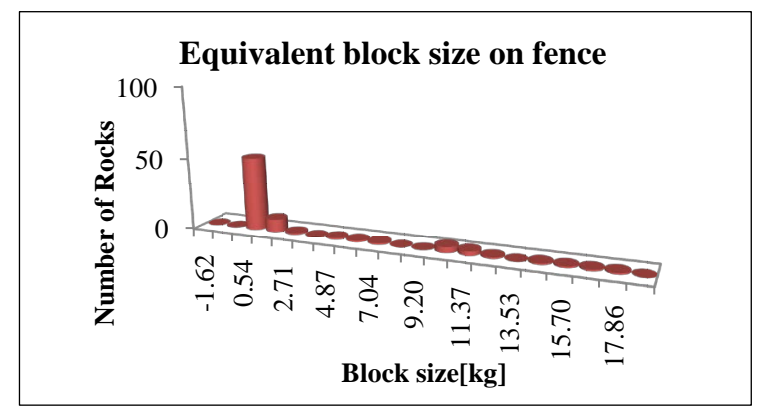

Figure 8. Equivalent block size for Brighton fences.

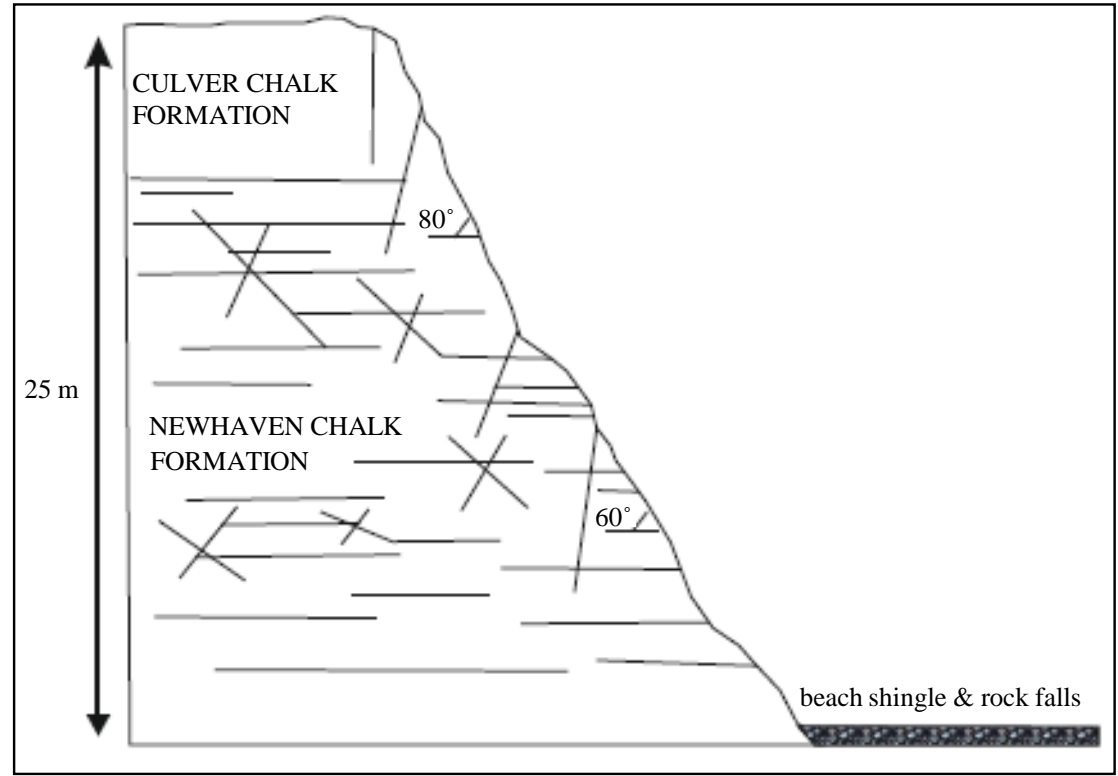

Figure 9. Drawing of cliff profile of Saltdean.

\section{Equivalent block size on beach shingle}

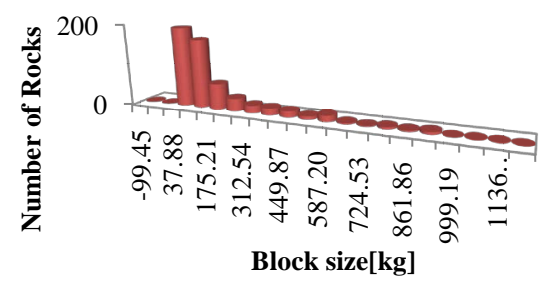

Figure 10. Equivalent block size for Telescombe Cliffs.

\subsection{Peacehaven}

Peacehaven under-cliff walk doesn't have any shingle banks, catch-nets, or fences. There are only the protective wall (against the cliff face) and the sea wall (Figure 11). The results from RocFall analysis showed that rockslanding on the protective wall will reach an end point as far as the sea wall. Rocks falling from the highest point of the cliff will reach a distance beyond the sea wall as a result of high bouncing. $40 \%$ of rocks end point is between the cliff face and $1 \mathrm{~m}$ away from cliff face. $60 \%$ of the rocks will have end points beyond that. Most falling blocks range in size from debris to $1 \mathrm{~kg}$. The rest of the falling rocks range in size between $1 \mathrm{~kg}$ to $16 \mathrm{~kg}$. Rarely falling block size would reach $36 \mathrm{~kg}$ (Figure 12). 


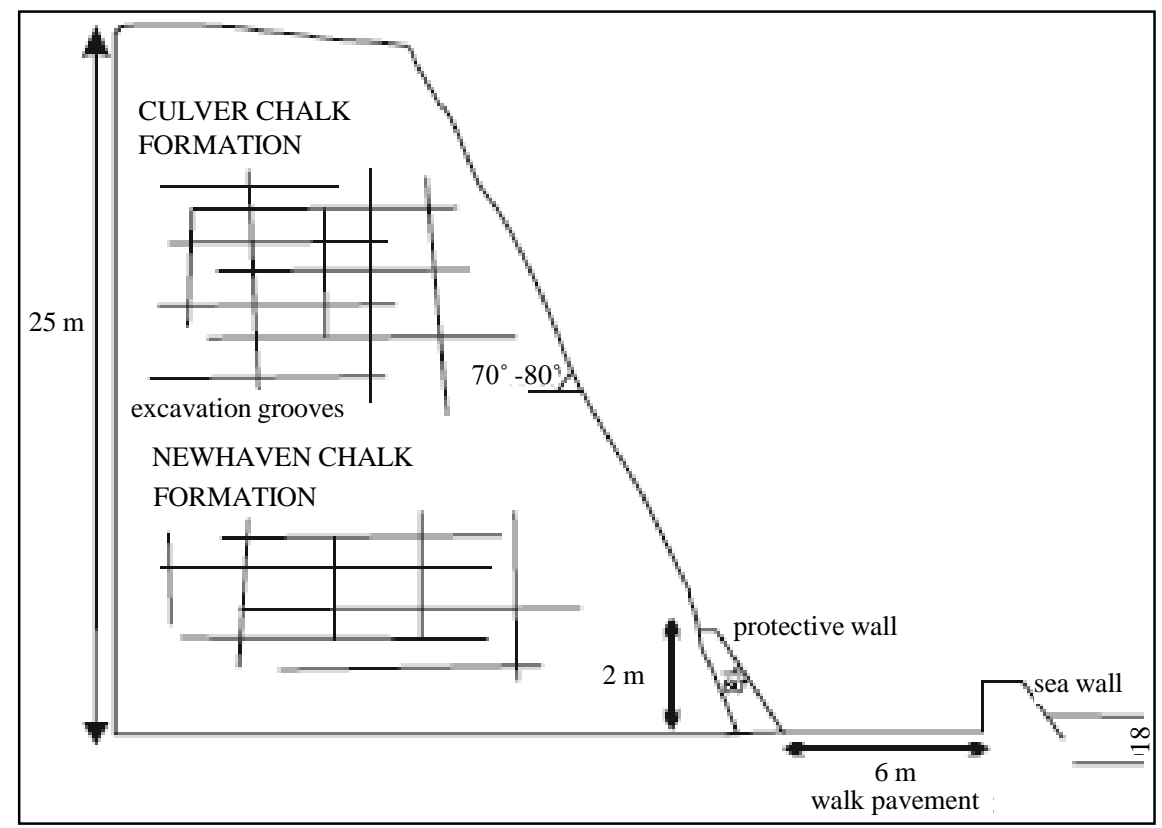

Figure 11. Drawing of cliff profile of Peacehaven under-cliff walk.

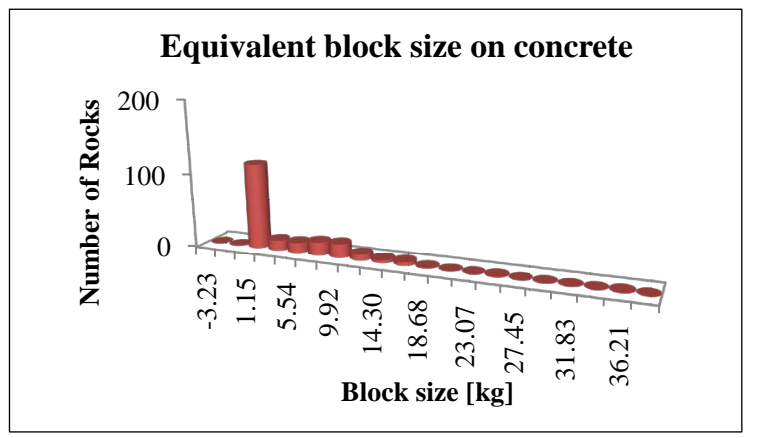

Figure 12. Equivalent block size for Peacehaven undercliff walk.

\subsection{Newhaven}

Failure in Newhaven is mostly mud slides from the top Paleogene deposits (Figure 13). Also chalk failure can occur in Newhaven Cliffs; mostly planar failure. RocFall analysis showed that most rocks have an end point close to the cliff face. $40 \%$ of rocks fall between the cliff face and $2 \mathrm{~m}$ away from the cliff face. The rest fall between $2 \mathrm{~m}$ and $10 \mathrm{~m}$ away from the cliff face and only $2 \%$ of the rocks falling might reach $15 \mathrm{~m}$ away from the cliff face. Most rocks have a mass ranging between debris sizes up to $100 \mathrm{~kg}$. The maximum block size might reach almost $1000 \mathrm{~kg}$ (Figure 14).

\subsection{Seaford}

Planar and toppling failures are the most common in Seaford Cliffs (Figure 15). Rocks falling from Seaford Cliffs have an end point between the cliff face and $6 \mathrm{~m}$ away from the cliff face. The maximum distance a falling rock can reach is $15 \mathrm{~m}$ away from the cliff face and the maximum block size might reach about $900 \mathrm{~kg}$ (Figure 16).

\subsection{Cuckmere Haven}

The dominant types of failure in Seven Sisters Cliffs are vertical and toppling failures as a result from the exten- 


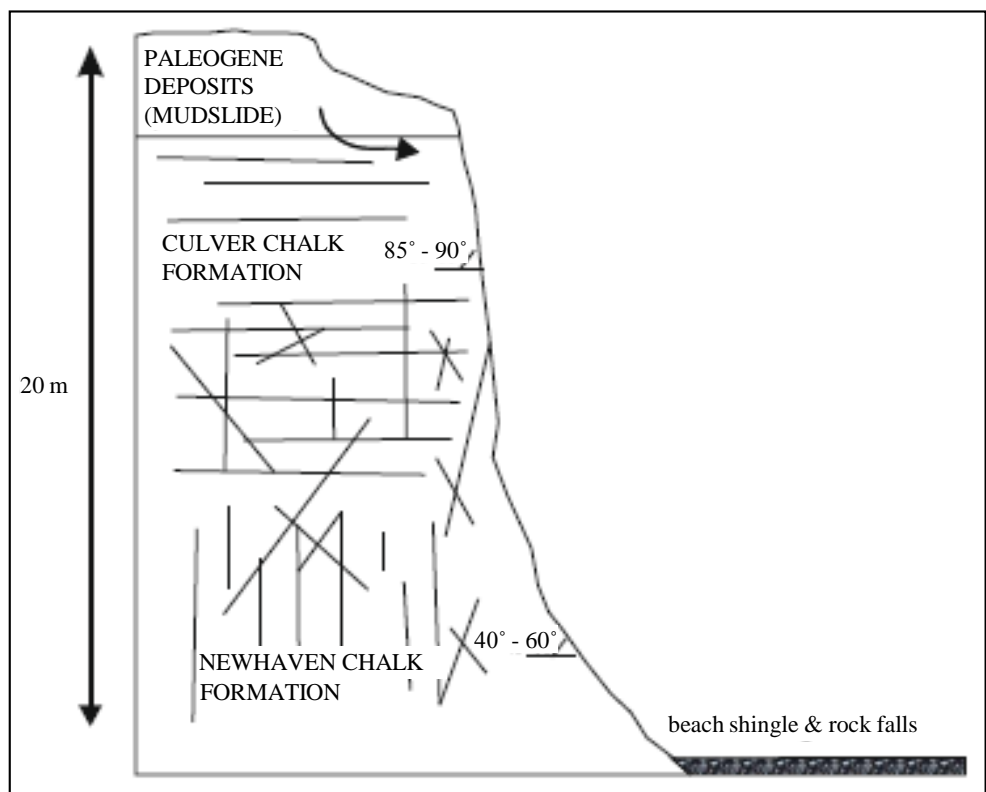

Figure 13. Drawing of cliff profile of Newhaven.

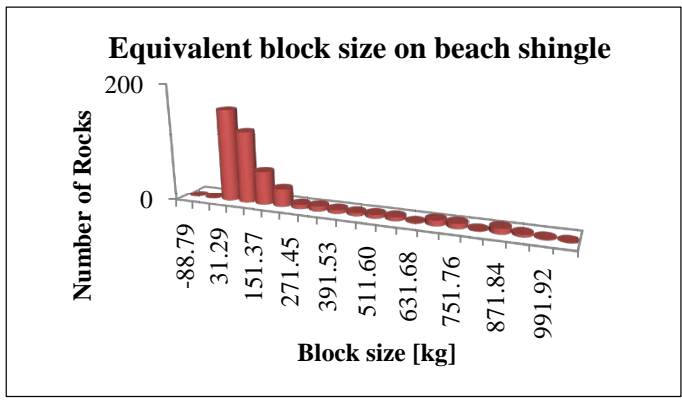

Figure 14. Equivalent block size for Newhaven Cliffs.

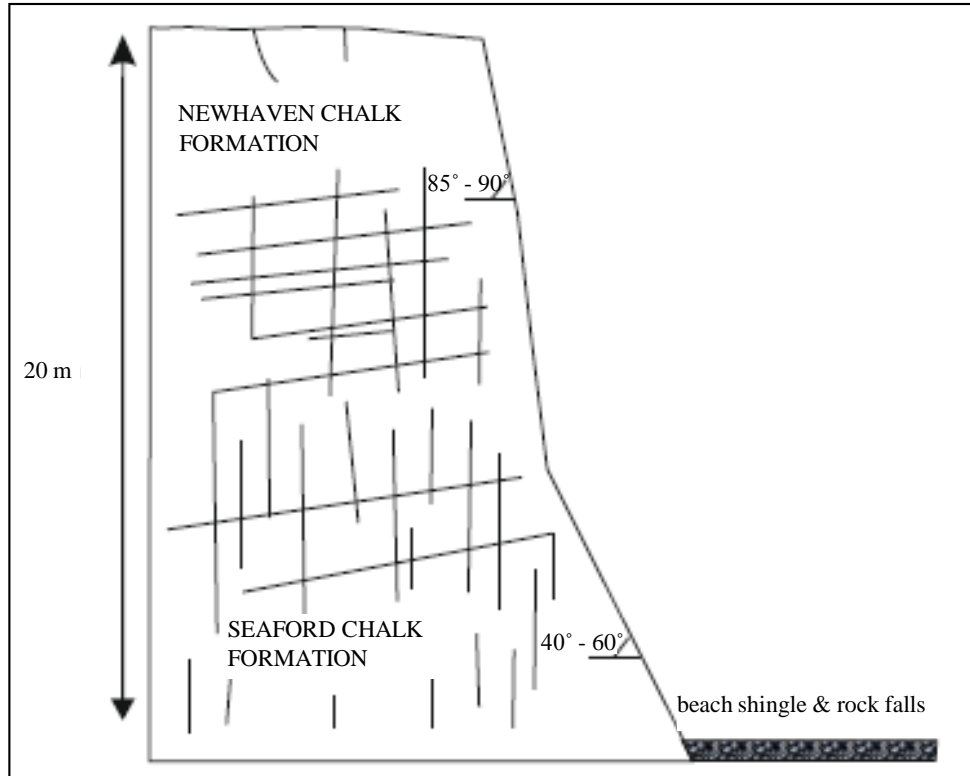

Figure 15. Drawing of cliff profile of Seaford. 


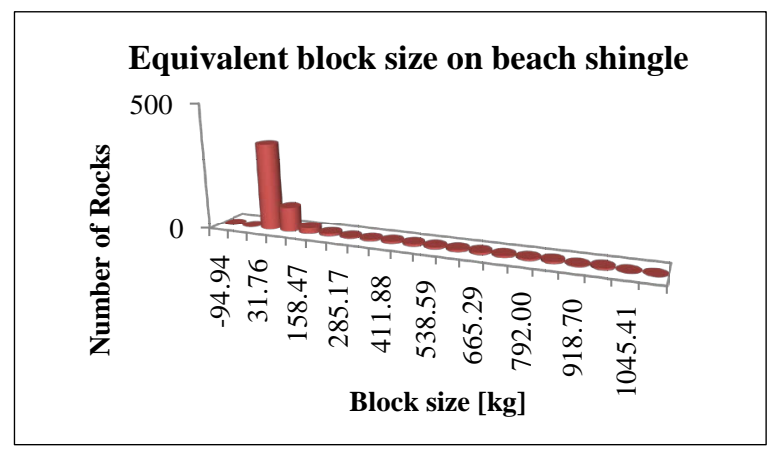

Figure 16. Equivalent block size for Seaford Cliffs.

sive vertical jointing in the chalk units in the area (Figure 17). 25\% of the rocks falling from the Seven Sisters cliff will have an end point $5 \mathrm{~m}$ away from the cliff face. $40 \%$ of the rocks will have an end point between $5 \mathrm{~m}$ and $10 \mathrm{~m}$ distance away from the cliff face. The maximum distance rocks can reach is $20 \mathrm{~m}$ away from the cliff face and the maximum block size is $2600 \mathrm{~kg}$ (Figure 18).

\subsection{Birling Gap}

All types of failures might occur in Birling Gap; stepped failure, wedge, toppling, and vertical failures (Figure 19). Rocks falling from the $100 \mathrm{~m}$ high cliffs in Birling Gap might reach an end point of $60 \mathrm{~m}$ away from the cliff face. About $10 \%$ of the rocks will reach a distance between 30 and $40 \mathrm{~m}$ away from the cliff face. The largest block size is about 10,000 kg/10tones (Figure 20).

\subsection{Beachy Head}

Toppling and vertical failures are the most common in Beachy Head but in a complex manner involving the different types of chalk formations (Figure 21).

Rocks falling from Beachy Head Cliffs might reach an end point of $80 \mathrm{~m}$ away from the cliff face. The range of end point distances of falling rocks is between the cliff face and $20 \mathrm{~m}$ away from the cliff face. The rest of the rocks will reach a distance between 30 and $40 \mathrm{~m}$ away from the cliff face. The largest block size might exceed 13,000 kg/13tones (Figure 22).

\subsection{Eastbourne}

The failure in Eastbourne is completely different to other failures in the area. Chalk in Cow Gap cliffs slide in a circular manner as a result of underlying Gault Clay movement (Figure 23). Rocks falling from Eastbourne cliffs will land next to the cliff and bounce to reach an average end point of $4 \mathrm{~m}$ away from the cliff face. The maximum distance rocks falling from the cliff might reach is $20 \mathrm{~m}$ away from the cliff face. The falling block size ranges between debris sizes and $200 \mathrm{~kg}$ reaching a maximum of $1800 \mathrm{~kg}$ (Figure 24).

\section{Conclusion}

The effect of weathering, sea erosion, and properties of chalk altogether play a major role in relation to the rock fall in the area. Many factors influence the falling block size and its end point. The steeply dipping chalk cliffs are mostly threatened by vertical and toppling failures which result in the failure of the largest block sizes reaching the furthest distance. Also the shape and type of falling rocks in addition to the cliff roughness and height of failure alter the end point of these rocks. Though RocFall doesn't take into account factors affecting the size and extent of rock fall, the results were very reasonable to what was observed and similar values were obtained during site reconnaissance and from previous failures. Although the time of failure cannot be predicted, knowing the areas where major rock failure might occur is very helpful in limiting risks and financial costs. According to the analysis Birling Gap and Beachy Head areas are of the highest risk where failures are major in relation to size and extent. Other areas will also encounter failure but in less excessive way. Therefore mitigation is suggested to be carried out knowing that the cliffs are highly weathered and very weak, especially in the East- 


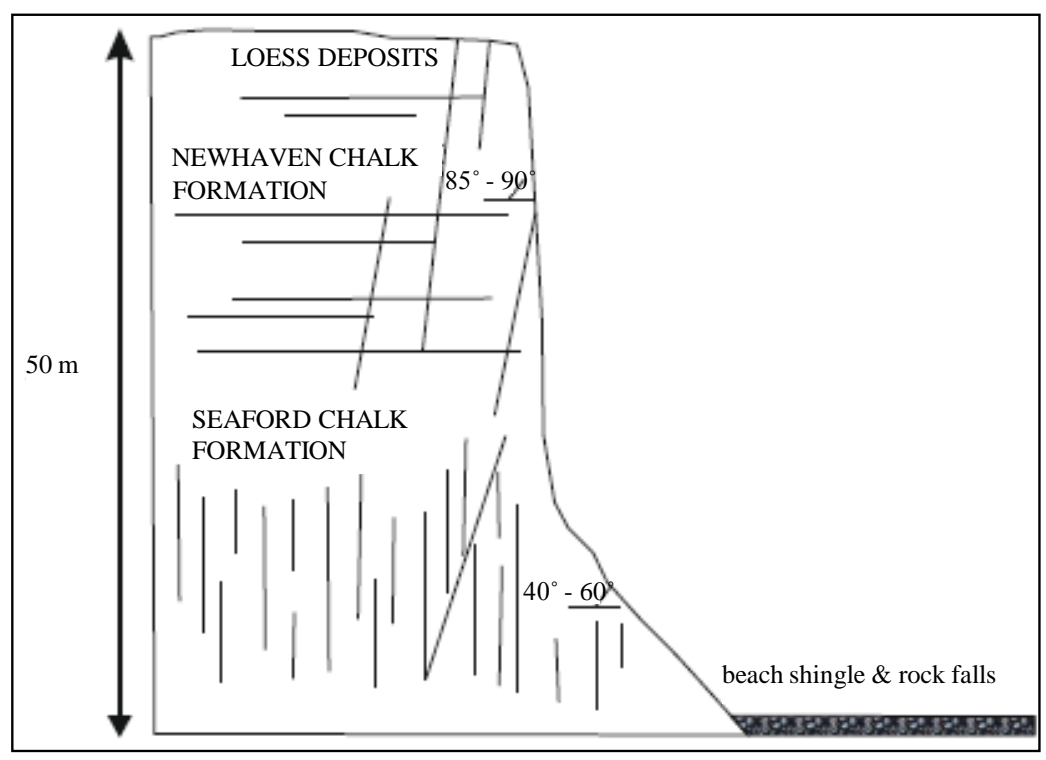

Figure 17. Drawing of cliff profile of Cuckmere Haven.

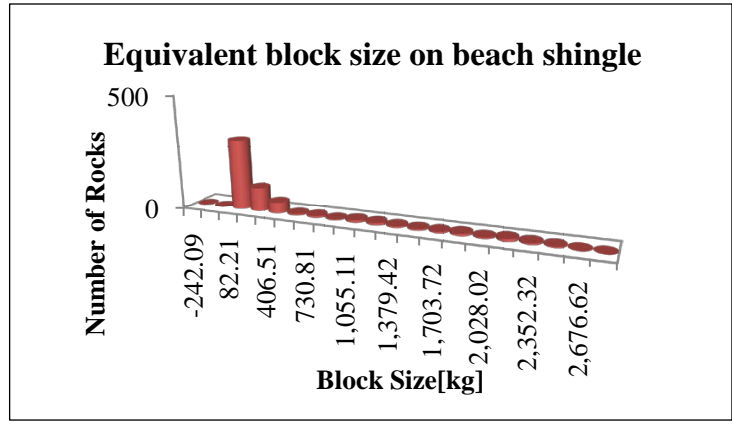

Figure 18. Equivalent block size for Seven Sisters Cliffs.

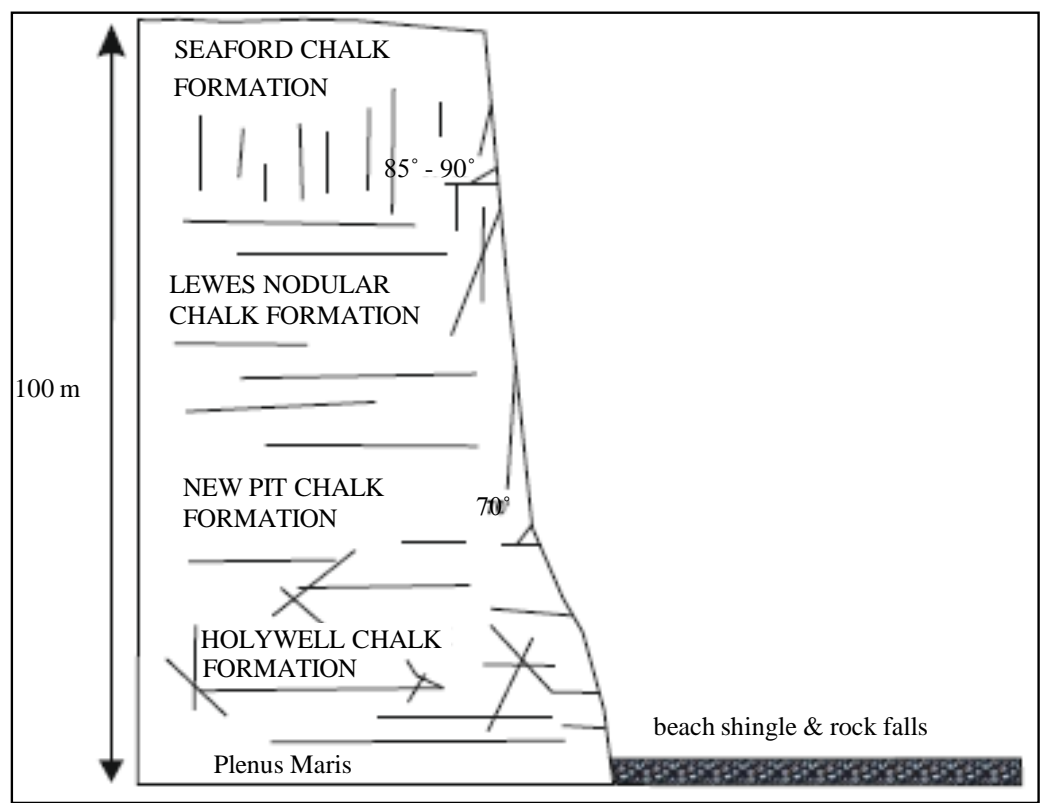

Figure 19. Drawing of cliff profile of Birling Gap. 


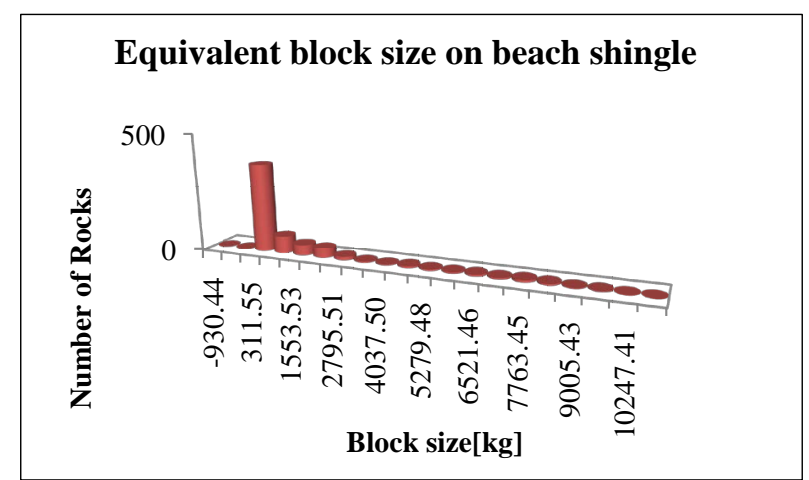

Figure 20. Equivalent block size for Birling Gap Cliffs.

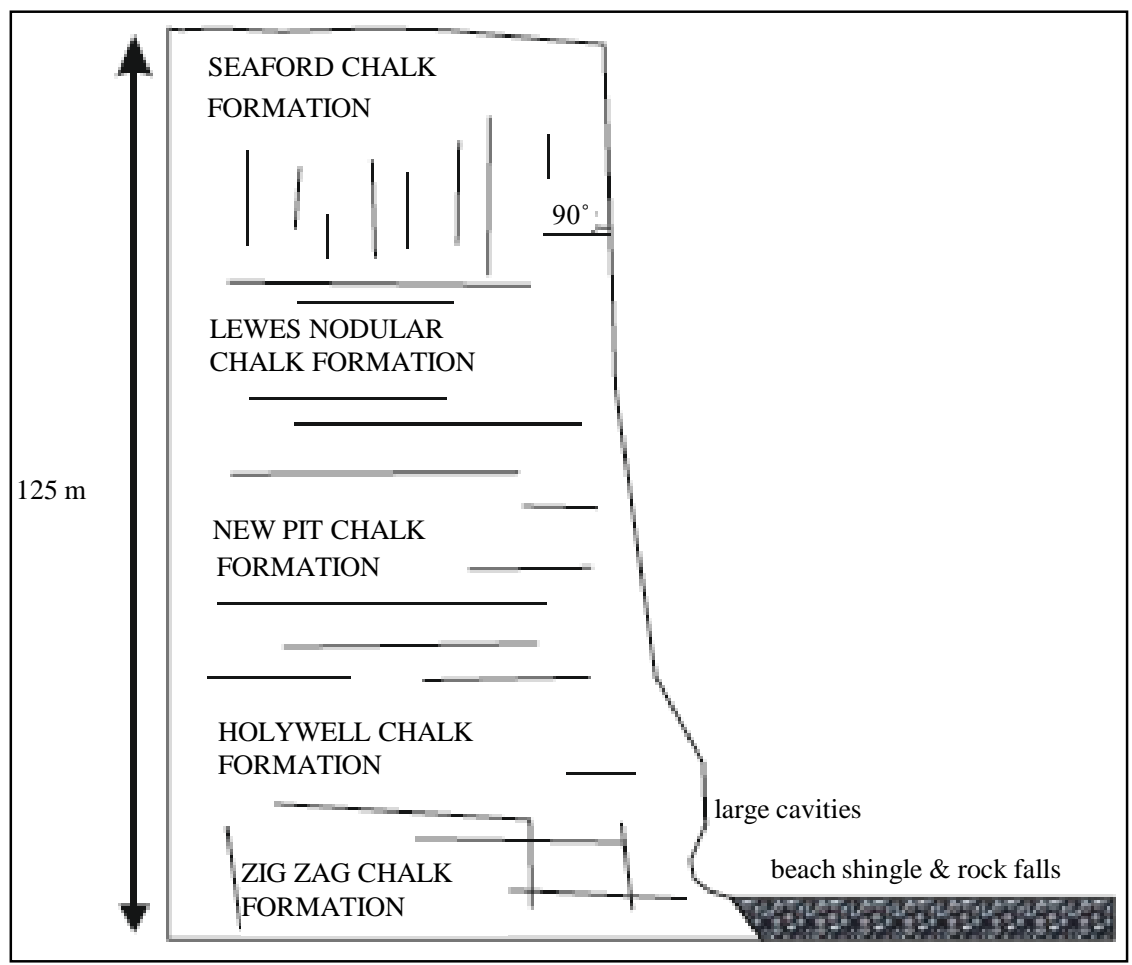

Figure 21. Drawing of cliff profile of Beachy Head.

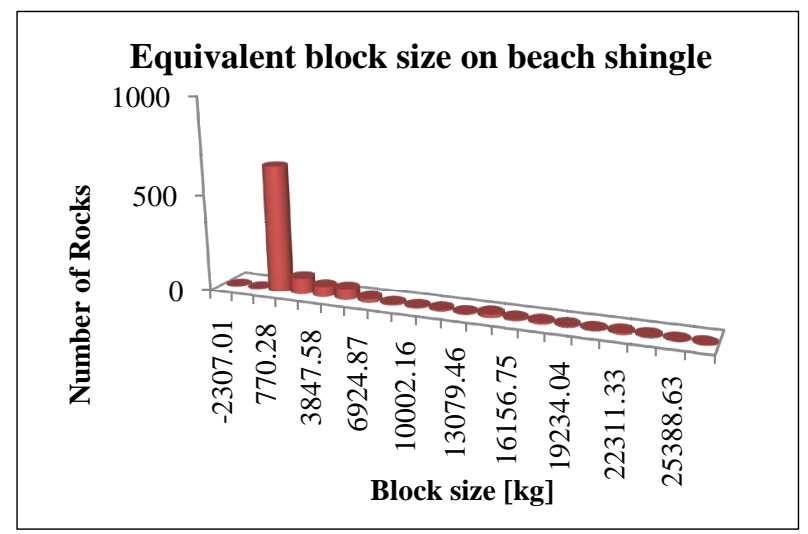

Figure 22. Equivalent block size for Beachy Head Cliffs. 


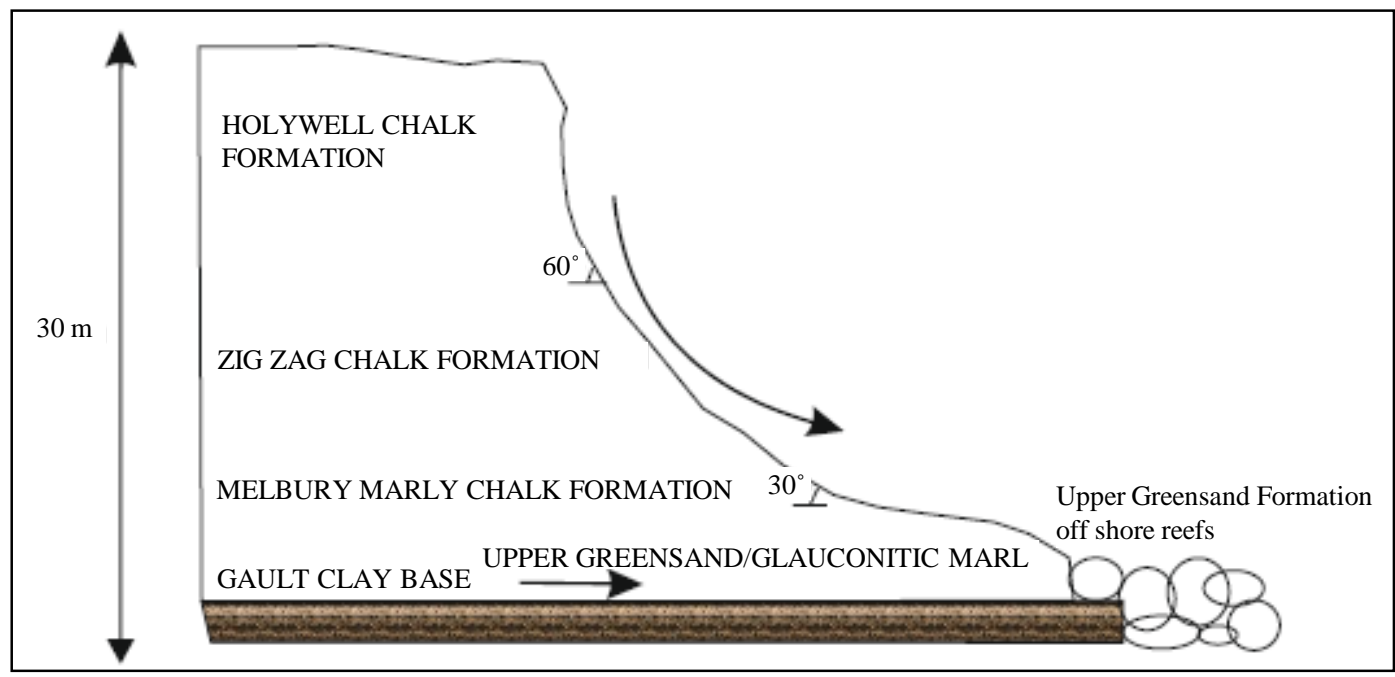

Figure 23. Drawing of cliff profile of Eastbourne.

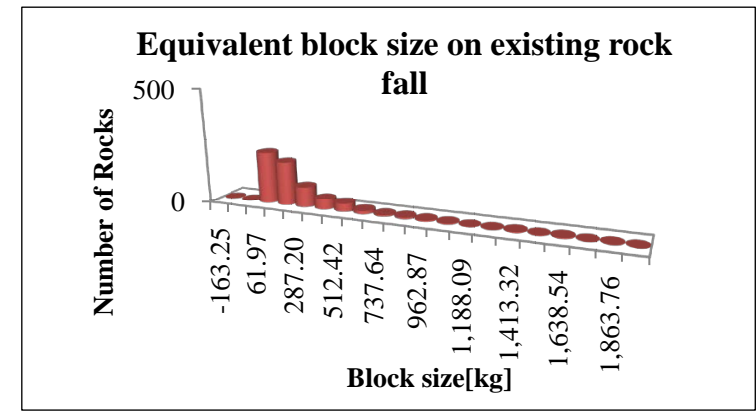

Figure 24. Equivalent block size for Cow Gap Cliffs.

ern part of the study area and as a result of the geological and environmental conditions there will be further cliff collapses in the future.

\section{References}

[1] Mortimore, R.N., Wood, C.J. and Gallois, R.W. (2001) British Upper Cretaceous Stratigraphy. Joint Nature Conservation Committee, Peterborough.

[2] Bell, F.G. (2007) Engineering Properties of Soils and Rocks. 2nd Edition, Blackwell Science, Oxford.

[3] Cheng, Y.M. and Lau, C.K. (2008) Slope Stability Analysis and Stabilization: New Methods and Insight. Routledge, USA.

[4] Särkkä, P. and Eloranta, P. (2001) Rock Mechanics: A Challenge for Society. International Society for Rock Mechanics. 